Política y Sociedad

ISSN: $\quad 1130-8001$

ISSN-e: $1988-3129$

COMPLUTENSE

http://dx.doi.org/10.5209/POSO.54362

\title{
El ethos creativo: debates y diagnósticos sobre el nuevo imperativo moderno
}

\author{
Celso Sánchez Capdequí ${ }^{1}$
}

Recibido: 22-01-2017 / Aceptado: 04-10-2017

Resumen. El texto pretende explicar la emergencia de la creatividad como idea e ideal de la modernidad tardía. Si la visión de la sociología clásica define la modernidad como la hegemonía de la racionalidad instrumental, en los últimos cuarenta años el arte es el centro de la representación de la realidad. Arte y ciencia conviven en diferentes campos de la vida social. El artista ha sustituido al especialista como modelo de actor social y la acción creativa se ha convertido en principio de normalidad social. Los actores sociales no solo quieren crear, deben hacerlo y ser originales. La creatividad define la vida cotidiana e introduce nuevas expresiones de dominación. La modernidad tardía necesita una propuesta de crítica de la creatividad social.

Palabras clave: creatividad; modernidad; arte; acción social; crítica.

\section{[en] The Creative Ethos: Debates and Diagnoses about the New Modern Imperative}

Abstract. The text intends to explain the emergence of creativity as idea and ideal of late modernity. If the vision of classical sociology defines modernity as the hegemony of the instrumental rationality, in the late forty years the art is the core of the representation of reality. Art and science coexist in different fields of the social life. The artist has replaced the specialist as model of social actor and the creative action has become principle of social normality. The actors not only want to create, they must to do it and to be original. The creativity defines the daily life and introduces new expressions of domination. The late modernity needs a proposal of critique of social creativity.

Keywords: Creativity; modernity; art; social action; critique.

Cómo citar: Sánchez Capdequí, C. (2017): "El ethos creativo: debates y diagnósticos sobre el nuevo imperativo moderno", Política y Sociedad, 54(3), pp. 621-640.

Sumario. 1. Introducción: la emergencia del ethos creativo. 2. El despertar de la creatividad. 3. Redefinición de la modernidad: expansión de la estética. 4. Genealogía de la subjetividad creativa.

5. Crítica de la creatividad. 6. Bibliografía.

Universidad Pública de Navarra (Departamento de Sociología) (España).

E-mail: celso.sanchez@unavarra.es 


\section{Introducción: la emergencia del ethos creativo}

Hasta fechas recientes se daba por descontado que el debate sobre la modernidad había llegado a su fin. El advenimiento de la postmodernidad suponía, según JeanFrançois Lyotard (1987), que se trataba de un ser decrépito, agonizante y en claro proceso de degeneración. A su juicio, habían pasado los tiempos de los grandes relatos, representados, de manera señera, por la modernidad, cuya narrativa hegemónica había desembocado en un universalismo etnocéntrico basado en simplificaciones y en reductivismos y causante de efectos trágicos para la condición humana. El curso lineal, autónomo y progresivo de la historia saltaba por los aires. La fe en un futuro redentor se difuminaba $\mathrm{y}$, con ella, la presencia de un actor abnegado y disciplinado que le impulsaba. A partir de ese momento, los fragmentos y su variedad se convertían en la materia del mundo. Las formas de expresión del ser humano se multiplicaban en un transcurso histórico sin un sentido pre-dado, zarandeado por las contingencias de la acción humana e inscrito en un horizonte temporal sin utopías y abierto a lo desconocido.

Sin embargo, el debate en torno a la modernidad vuelve al centro de la reflexión intelectual. En la actualidad enfoques como el de las modernidades múltiples (Eisenstadt, ed., 1986), el choque de civilizaciones (Huntington, 2001), las modernidades enredadas (Conrad y Randeria, 2002), las variedades de la modernidad (Schmidt, 2006), entre otros, dan cuenta de una cuestión que vuelve por donde solía y cuyo buen estado de salud desmiente a aquellas voces que presagiaban su muerte inminente. Todos ellos tienen en común el hecho de que, de una u otra forma, la modernidad se conjuga en plural, de que descubren formas y expresiones de la misma que había ocultado el metarrelato de la modernidad triunfante de cuño judeo-cristiano. El centro de la discusión no es "la" modernidad, sino "las" modernidades y las formas múltiples de serlo por parte de diferentes programas culturales a lo largo de la historia. La variedad se reivindica como foco del debate y, con ello, las tensiones interculturales que han sido subsumidas en la investigación de una teoría social centrada en una visión histórica providencialista. Aparecen, por ello, expresiones como "las civilizaciones axiales", "la modernidad confuciana", "la modernidad hindú", "el capitalismo renano", "el capitalismo japonés", etc., como novedosos sujetos sociales desconocidos en los inicios de la modernidad.

En este contexto de renovación del discurso científico sobre la modernidad tiene lugar una reflexión de enorme alcance que se inscribe en la tradición de pensamiento que trazan la filosofía y sociología en los dos últimos siglos y en la que, a la luz de las instituciones y prácticas sociales relevantes en nuestro tiempo, se cuestiona el modelo de la sociedad moderna, basada en rígidas pautas de acción y organización social que siguen reglas económicas (Weber, Marx) o morales (Durkheim, Parsons) y que frenan la intervención espontánea y creativa del actor. En este caso, el efecto paralizante de la racionalidad medios-fines que promueve el funcionamiento de la maquinaria capitalista a escala global queda fuera de toda duda. Sin embargo, la actual expansión del simbolismo, la figuración y la sensibilidad estética entre amplios sectores y ámbitos de la sociedad obliga a los científicos sociales contemporáneos a meditar sus causas y a sopesar el estado actual de las imágenes y argumentaciones del pasado que hablaban de la 
hegemonía de la racionalidad instrumental y/o normativa en el transcurso de la modernidad. La experiencia reciente del vigor de la idea de creatividad estética en dominios sociales como el sistema productivo, educativo, político, científico, identitario y afectivo de la sociedad actual, insta al replanteamiento del estado de una modernidad cuyos diagnósticos más celebrados veían en ella un proceso de racionalización y desencantamiento del mundo (Weber) ajeno a las consideraciones motivacionales inherentes a la vida social. La productividad definía los límites inclusivos de los actores bajo etiquetas como "empresario", "trabajador", "burócrata", "operario", "beneficio", "plusvalía", entre otras, dejando para la periferia de los excluidos sus imágenes antagónicas como "artista", "bohemio", "improductivo", "subversión" "ociosidad", "juego", "desviación", etc.

La creatividad ocupa el centro neurálgico de las sociedades contemporáneas. Un cambio de enorme calado se ha producido en los últimos cuarenta años en el seno de nuestros hábitos y rutinas. La modernidad se ha renovado desde dentro y a partir de procesos endógenos que cristalizan en la idea de creatividad estética. La dimensión motivacional de la experiencia creativa se ha hecho fuerte en las tramas narrativas de la sociedad y su disposición semántica se ha desplegado hacia todos los rincones de la sociedad. El capitalismo burgués de origen ascético ha mutado su metabolismo, se ha despojado del espíritu racionalizador de origen y ha dado entrada a aspectos sensitivos y afectivos desconocidos hasta fechas recientes. El nuevo capitalismo estético produce sueños, ilusiones y experiencias (Harvey, 1998). Despierta estimulaciones afectivas de manera constante y se dirige a un público que se entrega incondicionalmente a su ilimitada capacidad de sorpresa. Pero donde la creatividad constituye el centro vertebrador de los actuales hábitos y rutinas sociales es en la idea de normalidad. Aquí radica el aspecto inédito de sus transformaciones recientes. La creatividad, el acto y el actor creativo se han convertido en normales. Más en concreto, en norma. Si antes eran la expresión de lo extravagante y lo desviado, en la actualidad trazan los bordes de lo ordinario, lo rutinario y lo previsible. Y ello hasta el punto de que vivir al margen del dictado de la originalidad conlleva el riesgo de quedar fuera del núcleo denso de la sociedad. Hoy no ser original significa, sin más, no-ser, vivir experiencias de frustración, exclusión y precariedad.

El hecho es que la democratización de la experiencia creativa supone que el modelo del artista rivaliza con el criterio propiamente productivo-funcional en la zona decisiva de las prácticas sociales. El fondo expresivo del artista, el colorido que impregna todo lo que hace, su contacto permanente con lo lúdico, lo experimental, lo aleatorio, hacen de él un modelo social de validez incuestionable. El actor contemporáneo se siente movido por la búsqueda de originalidad. Y no como mera experiencia de deleite, también como expectativa social. Como dice Andreas Reckwitz, "se quiere ser creativo y se debe ser creativo" (2012: 10). Y ello en la profesión, la familia, las relaciones afectivas y en la dimensión identitaria. Ser creativo se ha convertido en el destino de nuestro tiempo. Los grandes riesgos biográficos tienen lugar en esa zona limítrofe en la que se juega el reconocimiento (y/o el desdén) del público respecto a nuestras propuestas creativas de originalidad.

Por otro lado, no se trata de un modo de organización social que culmina un proceso de liberación de largo recorrido e impuesto por una razón oculta en las 
tramas secretas de la historia. Lejos de explicar su surgimiento a partir de un automatismo histórico que imprime un destino y un recorrido a priori a la acción y a la historia social, la creatividad constituye el imaginario simbólico de nuestra sociedad que ha nacido con motivo de determinadas prácticas sociales y procesos de cambio social. El imaginario de la creatividad es obra de la creatividad del imaginario. Nunca un punto final o culminante impuesto por una lógica inmanente. La presencia de la creatividad puede ser explicada y glosada científicamente sin tener que acudir a esquemas que hablan de un proceso mecánico de liberación humana. Curiosamente, la experiencia creadora como práctica generalizada deja heridos en la cuneta. Aparecen nuevos modos de opresión y desigualdad impuestos por un filtro cultural que separa entre incluidos y excluidos. No en vano, no todos los actores disponen de las mismas condiciones de partida ni de iguales resultados en sus procesos de creación.

\section{El despertar de la creatividad}

Durante los últimos 40 años la creatividad se ha convertido en objeto de investigación social, producto del papel relevante que ha pasado a ocupar en los modelos de vida actuales. Así como en los episodios decimonónicos de la filosofía y sociología modernas su protagonismo fue escaso, hoy constituye un elemento sustantivo en la biografía del actor contemporáneo. Sin embargo, se han dado diferentes acercamientos al problema de la creatividad. No solo ha existido un único enfoque. Ello obedece a que se trata de un concepto que incluye distintos dominios semánticos de la experiencia que conviven y se solapan en todo hecho social pero que, desde el punto de vista analítico, ofrecen una autonomía temática y semántica entre ellos.

Para una correcta delimitación del argumento que viene a continuación, podrían distinguirse diferentes dominios semánticos que remiten igualmente al hecho creativo.

1) Dominio metafisico de la creatividad. En este caso el protagonismo recae sobre la idea de ser que se ha privilegiado en el pensamiento occidental desde la filosofía griega hasta bien entrado el siglo 20. Ya fueran las Ideas de Platón, la Trascendencia divina de la filosofía escolástica, el Espiritu de Hegel, el Progreso Técnico de la modernidad judeo-cristiana, la mirada filosófica acerca de lo que es ha ofrecido respuestas "deterministas" en las que el dibujo de un orden metafísico clausurado, esencial e inmutable ha definido la zona noble de la realidad. La sustancia, ya sea como orden trascendente o como orden inmanente, se concibe como lo real por su estabilidad y a-temporalidad frente a la precariedad del ámbito de los accidentes definido por su inconsistencia y alteración constante. Entre estos, la creatividad ha sido menospreciada por el hecho de que su capacidad de transformación de la experiencia contraviene el modelo de clausura ontológica que define las claves de la reflexión filosófica occidental. Sin embargo, desde los años 70 , pensadores como C. Castoriadis (1989), A. Touraine (1987), M. Maffesoli (1996), G. Durand (1990), entre otros, ponen en solfa este enfoque filosófico. La noción de imaginario (Castoriadis, 
1989) que tratan estos autores introduce como parte nuclear de la reflexión la metáfora de magma, en especial en el caso de Castoriadis, como el atributo de inacabamiento de lo real y como su capacidad de autoalteración permanente. La realidad queda (in-)definida como lo por-ser, no por meramente ser. A través del magma se acentúa, no tanto un dibujo eterno y definitivo de lo real, como la apertura de la experiencia para reorganizarse de múltiples formas. Estos autores plantean que lo que hay es des-orden e indeterminación, no en el sentido privativo de ausencia de determinación, sino de creación, de surgimiento de otros órdenes, leyes, valores y esquemas de convivencia (Castoriadis, 1988: 64-77).

2) Dominio histórico-civilizacional de la creatividad. En este ámbito de la experiencia la creatividad ofrece otro sesgo de enorme relevancia. Se remite al momento histórico en el que, con el surgimiento de las civilizaciones axiales, tiene lugar el despertar de la autoconciencia humana como agente creativo. Este hecho introduce un punto de no-retorno en la memoria de la especie humana toda vez que supone la revelación de algo que le constituye desde su aparición en la tierra: la capacidad de intervención renovadora en el mundo. La aparición de la reflexividad constituye un avance evolutivo de alcance estructural y universal (Donald, 1991). Se trata de algo que transforma inexorable e irreversiblemente la relación del hombre consigo mismo y con la realidad. K. Jaspers (1965), en primer lugar, seguido por B. Schwartz (1975), S. Eisenstadt (1986) y R. Bellah (2011), coinciden en subrayar que el surgimiento de las civilizaciones axiales como el Judaísmo, el Cristianismo, el Budismo, el Confucianismo, la Filosofía griega, contribuye al cuestionamiento de la presunta determinación natural de la existencia humana. Estaríamos ante la aparición del pensamiento de segundo orden (Elkana,1986: 40-64), ya que no solo se elaboran sistemas teóricos de orden filosófico, matemático o jurídico, sino que se meditan sus condiciones de posibilidad. Se empieza a pensar el pensamiento dando impulso a los procesos de ideación universal y abstracta. De la mano de los nuevos estamentos intelectuales como los profetas judíos, los literati chinos, los sacerdotes budistas, los filósofos griegos, esas minorías creativas (Toynbee, 1981: 321) encarnan una actitud de lenta democratización de la creatividad a lo largo de la historia en la que las sociedades se cuestionan el mundo y, más importante, las condiciones de su percepción. La particularidad de las civilizaciones axiales se centra en factores como la trascendencia y la creatividad como las notas más destacadas de las mismas. En concreto, frente a las culturas preaxiales (previas a la aparición de la escritura y sustentadas en una visión monista relativa al papel autorregenerador e inmanente del cosmos natural), las civilizaciones axiales priorizan desde sus inicios un enfoque dualista basado en la trascendencia y la inmanencia en el que la noción de salvación ultramundana se convierte en esquema organizador de la existencia. Ello obliga a los actores a diseñar creativamente la respuesta religiosa a la pregunta de la salvación del alma. La orientación ética de la conducta abre la puerta a una autoconciencia que empieza a cuestionar los límites de todo tipo, entre ellos, el político. La cuestión de la legitimación del poder político surge en este período histórico y llega hasta nuestras sociedades.

3) Dominio social de la creatividad. En este apartado se debate la dimensión renovadora de la interacción social. Este rasgo estructural de la aventura 
moderna tiene ya como precedente la herencia axial referida al descubrimiento de la capacidad creativa de la vida intersubjetiva. Aunque la sociología nace como ciencia de lo social que investiga la singularidad moderna del cambio social, en la teorización sociológica han predominado desde sus inicios esquemas de pensamiento centrados en el dominio técnico del mundo y dispuestos sobre formas de pensamiento mecanicistas. La narrativa de la secularización en sus múltiples expresiones (revolución, progreso, desarrollo) expresa esta corriente dominante en el imaginario sociológico. En este contexto el cambio social no se sigue de la acción social debido a que esta carece del impulso favorecedor de los procesos de renovación social. En los años 90 Hans Joas publica su libro titulado La creatividad de la acción (1992), que supone un cambio sustancial en la sensibilidad sociológica acerca de la acción en la medida en que no entiende la creatividad como un modelo de acción más (junto al marxista, funcionalista, sistémico, etc.), sino como el más de innovación y cambio que introduce toda acción. Bajo la expresión teorías de la constitución en las que incluye a autores como A. Touraine (1987), C. Castoriadis (1989), P. Bourdieu (1981), A. Giddens (1995), Joas constata un cambio de percepción en la teoría sociológica producida en torno a los años 70 en el que la sociología empieza a considerar la sustancia creativa de la acción en clara sintonía con el problema del cambio social. No puede haber una adecuada consideración de la realidad social si no se explican sus cambios, y estos no pueden ser explicados atendiendo únicamente a esquemas mecanicistas. En el trasfondo de esta reflexión se constata que sin la participación de los actores en esos cambios se desdibuja la idea o el ideal de autonomía que alienta la modernidad. Joas cuestiona los presupuestos epistemológicos de la reflexión sociológica centrada en el predominio de la racionalidad funcional como son el sujeto cartesiano distanciado cognitivamente del curso del mundo, el predominio de la subjetividad teórica sobre las razones secretas del cuerpo y la supremacía de la vida individual sobre la experiencia intersubjetiva. De este modo, abre las puertas a la noción de creatividad. Esta remite a ese momento en toda acción humana en el que los actores se saben partes de situaciones sociales que no dejan de desafiarles y exigirles respuestas de cambio, en los que la conciencia racional se siente invadida por la expresividad corporal y en los que tras toda subjetividad que actúa en el mundo es la intersubjetividad la que se juega su momento renovador. Sobre la base de los conceptos de situación social, expresividad corporal y el carácter formativo de lo intersubjetivo en lo subjetivo, Joas sienta las bases para repensar la creatividad de la acción como algo estructural en toda relación del hombre con el mundo en el que vive.

4) Dominio institucional de la creatividad. La singularidad del actual modelo de sociedad es que la creatividad ya no remite tanto a sus supuestos metafísicos, a sus orígenes histórico-civilizacionales o al carácter estructural de toda acción social, sino que constituye el núcleo semántico de la sociedad contemporánea (Heubel, 2002; Koppetsch, 2006; Reckwitz, 2012). Se ha actualizado como forma de vida, como narrativa social, como imaginario simbólico y como esquema de representación social. En este caso, la creatividad ya no es vista desde el enfoque de la mente individual, sino desde el trasfondo cultural de la vida social. Conforma el discurso de la época que proyecta una tipología social, 
un modelo de identidad y un código de lo inclusivo y lo excluido. Define los límites de representación y acción de los actores. La realidad queda definida por la creatividad. Así como los tres primeros dominios tienen un carácter estructural (metafísico, histórico-civilizacional y social), este dominio remite al carácter instituido e histórico que define a esta época creativa, según los movimientos contraculturales de los años 60, como edad de aquarius. Se ha hecho institución. De algún modo, los tres primeros forman parte de este último, que, en tanto histórico, podría haberse producido o no. Dicho de otro modo, el carácter metafísico, histórico-civilizacional y social interviene solapadamente en todo modelo de experiencia humana sin que este se tenga que definir, necesariamente, como creativo, como así lo atestiguan otros modelos de sociedad centrados en los valores de la moral aristocrática, la religión o el progreso técnico, en los cuales también han estado presentes. Sin embargo, la sociedad actual ha erigido a la creatividad en atributo nuclear y cohesionador de su tejido institucional. Modela sus pautas de acción y representación. Los actores ya no la viven como experiencia totalmente ajena a sus ocupaciones domésticas y profesionales, como una ruptura radical con los automatismos de la experiencia cotidiana o como algo propio de una minoría selecta. La creatividad se ha hecho normal y norma. Marca los límites de la realidad en nuestra experiencia social. Nos define como actores y como miembros de un modelo histórico de sociedad.

Tras esta aclaración previa que ha permitido fijar los contornos teóricos de la presente meditación, se trataría de delimitar a continuación el significado de lo que se entiende por experiencia creativa en el actual modo de vida. La necesidad de acotar el alcance de la creatividad se explica desde el momento en que esa experiencia ha caracterizado la aventura de la modernidad dada a la autotransformación del hombre y del mundo en el que vive. La identidad humana deviene problema y desafío en la medida en que su tendencia a intervenir en el entorno abre la puerta a lo desconocido como eterno compañero de viaje. Por otra parte, la creatividad no es un descubrimiento propiamente moderno. $\mathrm{Su}$ surgimiento histórico como atributo sustantivo de la existencia humana tiene lugar en episodios históricos muy distantes en el tiempo. Como ya ha sido dicho, se descubre como elemento inherente a la existencia humana en la era axial (s.V a.C.) junto a la idea de trascendencia que, al situar en el dominio trascendente de la voluntad divina las respuestas acerca de la salvación ultraterrena, convierte a los credos y las clerecías religiosas en fuerzas de control social que desactivan cualquier asomo de espontaneidad creativa y crítica. Si bien la capacidad autorreflexiva surge al mismo tiempo, la creatividad desde entonces ha ocupado un lugar marginal. La trascendencia y las instituciones reguladoras del dogma han orillado las facultades renovadoras de la acción social. Posteriormente, los automatismos de la visión histórica de la modernidad burguesa impidieron el protagonismo creador de los actores en los procesos de cambio social. En nuestra sociedad, sin embargo, explota su protagonismo y lo hace, no tanto cuestionando la realidad instituida, sino, sobre todo, instituyéndose como la realidad.

A continuación, se trataría de fijar adecuadamente el significado de creatividad que prevalece en los usos contemporáneos. En ningún caso estaríamos ante una dimensión sectorial de la vida moderna, la estética, que, según Kant, se orienta por 
el desinterés y constituye un fin en sí mismo; tampoco remitiría a algo puramente criticado y criticable por su carga ideológica, encubridor de relaciones de dominación, como pudo ser el enfoque de la Escuela de Fráncfort en relación a la industria cultural; de igual modo, la creatividad no remite a las condiciones trascendentales e imaginarias del orden social, tal y como plantean autores como C. Castoriadis, A. Touraine y M. Maffesoli; por último, no se trata de una capacidad de la que disfruta en nuestra sociedad solo una parte de la sociedad, la clase creativa de la que habla Richard Florida (2010).

La creatividad en nuestro tiempo quedaría definida a partir de dos elementos básicos:

Por un lado, el afán por alcanzar el sello de la originalidad. El individuo define su modo de vida a partir de una divergencia radical con lo normal y lo ordinario. Se trata de construir su biografía marcando diferencia, introduciendo lo inédito, proponiendo innovación. Destaca, por encima de todo, la creatividad entendida como "la conformación del individuo mismo" (Reckwitz, 2012: 11). Sin embargo, el trance creativo desborda los límites del arte. Se implanta como exigencia compartida en el conjunto de la sociedad. Apunta a un reto común para cualquier actividad, profesión y biografía, ya que todos ellos viven como destino ineludible ofrecer originalidad.

Asimismo, el modelo del artista, la figura del creador se consolida en este contexto como referente de la acción. En concreto, en el escenario postburgués el artista de las vanguardias cobra una relevancia de enorme calado. Su secreto no es otro que el de intercalar su expresividad en todas sus producciones artísticas. Estas no sólo representan, también evocan, sugieren y transmiten a un público atento y expectante ante las emociones portadoras de lo nuevo. Con ello su trabajo y su expresividad cobran vida al unísono como dos aspectos troncales de su vida dotados de continuidad.

De este modo, el artista normaliza su actividad fuera ya de los museos, pierde el estatus aurático de cuño romántico y se muestra en sociedad desprovisto de la excepcionalidad y la extravagancia de la bohemia parisina de inicios de la modernidad. El giro radical del artista cobra forma en sus prácticas en la medida en que el propio proceso creador pierde el aura de la mística creadora de una minoría social selecta. Se trata de un episodio abierto al público, en el que se trabaja en contacto con la mirada de los otros y en los que se expone el conjunto de fases y circunstancias del proceso creador. Este modelo del artista se adapta a la experiencia ordinaria y a la llamada a la transparencia que rige buena parte de los designios de la cultura de la imagen.

Un breve repaso al discurrir de la vida moderna permite constatar que la idea de novedad ha estado presente en su desarrollo histórico desde sus inicios. Convive con la modernidad desde siempre. Se trata de un concepto que evoca la dimensión dinámica que atraviesa los diferentes dominios de una sociedad que nace con el propósito de diferenciarse del tiempo lento de las sociedades tradicionales (Koselleck, 1993: 342 y ss.). Ya sea la revolución o la reforma política, la circulación de las mercancías, los avances científico-técnicos o la originalidad artística, la novedad imprime el carácter singular de este pasaje histórico. Si bien 
desde el punto de vista temporal, la novedad es pensada desde una diferenciación histórica entre pasado, presente y futuro, en cuyo despliegue se prestigia lo inédito frente a lo antiguo, desde el prisma estrictamente social remite a "ensamblajes de prácticas, discursos, formas de subjetivización y sistemas de artefactos, que no solo observan lo nuevo, y lo priorizan positivamente, sino que también lo exigen y lo producen activamente, lo incrementan y lo intensifican" (Reckwitz, 2012: 61).

En la experiencia de la modernidad pueden diferenciarse tres campos semánticos del concepto de novedad. En el primero, la novedad remite a la condición de nivel; el segundo, a la noción de incremento; y el tercero se refiere a la idea de estímulo. Estos tres campos semánticos, a su vez, se corresponden respectivamente con tres modelos de modernidad: la modernidad como perfección; la modernidad como progreso; y la modernidad como experiencia estética.

En el primer caso la novedad se concibe como una constelación inédita, progresista y racional que supera lo viejo. Con la consecución de este nivel, ya no existen mayores cotas de mejora o de desarrollo. Se habría alcanzado el umbral definitivo. Por ello, lo nuevo coincide aquí con "lo absoluto y lo revolucionario" (Reckwitz, 2012: 44). Tras la conquista de este nivel ya no es posible ni esperable "más novedad", si acaso, "mejoras incrementales". El modelo de esta noción de novedad es la revolución política y su despliegue es impulsado por el progreso político-moral de la humanidad. Este último se concibe desde el punto de vista de su culminación definitiva. El paso liberador y ascendente de la tradición al Estado de derecho, al Socialismo, a la Burocracia formal, a la arquitectura funcional, confirma esta idea de novedad.

Por otra parte, en la novedad entendida como incremento se constata la producción constante de novedad en el marco de un futuro sin fin, de un margen de mejora que no se avista en el presente. El modelo es el desarrollo incrementalista científico-técnico, la innovación económica y el modelo psicológico de la autooptimización. El concepto de incremento contiene "una alusión al más cuantitativo y a la ruptura cualitativa" (Ibidem: 45). Esta idea de novedad contiene una propuesta normativa de mejora de carácter duradero. Las instituciones y los sujetos que se organizan según este modelo de novedad tienden hacia transformaciones permanentes bajo la forma de un progreso gradual $\mathrm{u}$ ocasional.

Por último, la novedad como estimulación estética, dominante en el actual modelo de convivencia, ofrece rasgos bien distintos. Si bien remite a la producción dinámica de una serie de actos nuevos, no sigue la pauta de las connotaciones de progreso. Tampoco rige la línea recta que indica una mejora o incremento en el tiempo largo, sino una cualidad sensitivo-afectiva. Se trata de una secuencia de actos que cobran valor, concretamente, porque se diferencian de lo rutinario y la repetición en el horizonte temporal, porque se distancian, en tanto alteridad, de lo idéntico, de lo normal. Ahora la novedad es lo relativamente nuevo sin que, con ello, se exprese como una ruptura radical. El campo semántico de esta noción de la novedad corresponde a términos como lo interesante, lo original y lo inédito. La novedad no es ni el progreso ni el incremento, sino "el movimiento mismo, la serie de estímulos que promueven el interés. Lo nuevo se define por su diferenciación con los acontecimientos precedentes, por su diferencia como alteridad con lo idéntico o por su carácter en cuanto distanciamiento deliberado respecto a lo convencional" (Ibidem: 45). La nota más destacada de esta semántica social es la 
de un sujeto sensual semióticamente concebido bajo la creación de objetos y atmósferas que estimulan los sentidos y los sentimientos al modo en que opera el arte.

\section{Redefinición de la modernidad: expansión de lo estético}

Sin embargo, el concepto de lo estético que se corresponde con el actual modelo de vida requiere ciertas consideraciones aclaratorias que inciden en los cambios vividos en el tiempo presente. La principal es que se ha producido una mutación de envergadura en lo estético tal y como se he entendido en la modernidad en consonancia con el marco filosófico de Immanuel Kant (1999: 131 y ss.). Si en este el juicio estético remite a ese juicio humano que, en la búsqueda de la belleza, no tiene otro fin que el propio juicio como tal sin atender a las necesidades de los sentidos ni de la razón, en el trasfondo estético del actor contemporáneo destaca, con especial protagonismo, la afectividad y la emoción, en concreto, la experiencia sensible que deriva de la atracción ejercida sobre el actor por la ambientación estética que le rodea. La dimensión sensitiva se incorpora a las prácticas estéticas despertando la afectividad en la experiencia individual. Prevalece "el imperativo táctil" que "invita al espectador a la anulación de la distancia, a lo táctil o al touch" (Han, 2016: 13). La imagen más formal que elabora Kant se ve transformada por una estética que afecta, desata y moviliza las tramas libidinosas del individuo. Este se tiene que sentir interpelado de manera integral, de abajo arriba y al margen de consideraciones canónicas relativas a los códigos académicos y a los contenidos morales de la creación estética. La experiencia artística se vive sin distancia con el mundo y sin considerar la dimensión amenazante del afecto de la que habla Platón en los inicios de la filosofía occidental (Critchley, 2014: 55 y ss.).

Este aspecto de la dimensión afectiva y sensitiva del episodio estético nunca ha estado totalmente desatendido en la modernidad. Autores como W. Sombart, G. Simmel, T. Veblen, W. Benjamin, H. Marcuse, entre otros, han detectado el curso latente de su presencia en la musculatura industrial de sus primeros episodios. En especial, en la fase de transición del capitalismo de producción al capitalismo de consumo o estético, que se empieza a abrir paso en los años 40 de siglo pasado. Todos estos autores comparten la atención dirigida hacia la estetización de una producción que ya no se concibe, en el sentido de Marx, con el propósito de satisfacer necesidades materiales (valor de uso), sino de alentarlas y promoverlas simbólicamente (valor de cambio). Este paso tiene lugar en el curso interno del capitalismo, pero, en especial, de un proyecto moderno que, como se decía arriba, nunca ha prescindido totalmente del caudal afectivo y motivacional de las imágenes. Esta afirmación puede contrastarse en distintos apartados de la modernidad.

En primer lugar, la experiencia religiosa constituye un apartado social que despierta las dimensiones afectivas y emotivas de la intersubjetividad. En él la sociedad detiene los ritmos y los rigores cotidianos de la actividad rutinaria instrumental y activa el fondo creador e imaginario del colectivo en el que se renueva el anhelo irrenunciable de trascendencia (Durkheim: 1982). Se trata del momento extático en el que el grupo se identifica con la imagen aglutinante de la 
comunidad. Tiene lugar en los tiempos de fiesta y celebración del calendario social y su referencia es el valor sagrado que apuntala la cohesión del grupo.

Por otra parte, la vida política ofrece momentos de efervescencia colectiva que irrumpen fracturando el curso previsible y anodino de la historia y anunciando los procesos de renovación institucional y axiológica de la sociedad. Son esos episodios excepcionales en los que se vive la experiencia directa de la inauguración, fundación y constitución de algo nuevo (Arendt, 1998). En ellos la exaltación colectiva viene dada por el hecho de que los cambios sociales, por primera vez en la historia, son obra de la intervención humana. La revolución encarna esos episodios de entusiasmo que ven nacer algo cargado de esperanza y utopía.

Por último, la vida artística siempre ha tenido su espacio en la modernidad. A pesar de unos inicios en los que se sitúa en la periferia de la sociedad, su presencia minoritaria compensa emocionalmente la saturación cuantitativa del ethos burgués (Benjamin, 1994). Lo peculiar de esta es que su incremento y su expansión social ha venido para quedarse, para irrigar emocionalmente la cotidianidad y la rutina social y para llegar, en su momento actual, a definir el centro simbólico de las prácticas sociales. La estética es, por un lado, un elemento que desata emoción en su producción de signos, símbolos e ideas; por otro, una experiencia que arraiga en las tramas profundas de la vida contemporánea. Destaca por constituir parte sustancial de las rutinas y hábitos sociales.

Este arraigo obedece, en buena medida, a los artefactos técnicos que transmiten y canalizan la emoción colectiva. No son sus adversarios, sino condición de posibilidad de su irrupción social. En ellos se encuentran "los presupuestos para la producción duradera de los acontecimientos estéticos" (Reckwitz, 2102: 48). El carácter estructural del fondo emocional de esta modernidad sería favorecido y posible, de algún modo, por la presencia instrumental de la racionalidad teleológica. Esta sigue vigente en la sociedad contemporánea. Pero sus excesos de antaño han sido educados y compensados por una creatividad estética que exige medios técnicos al servicio de la estimulación motivacional y la originalidad individual y colectiva. Ya no se puede hablar por más tiempo de oposición entre lo estético y lo racional. En la modernidad postburguesa rige "una combinación necesariamente impura entre ambos" (Ibidem: 48). La racionalidad económica capitalista y su ramificación técnica no dirigen la vida social y los cambios históricos, antes bien, ofrecen "las condiciones estructurales que promueven la difusión social del dispositivo de la creatividad" (Ibidem: 48). Frente a la oposición que plantea Daniel Bell (1998) entre la modernidad ascético-burguesa y una modernidad incipiente de tipo estético-experimental, ambos modelos tienden a integrarse.

A continuación se trataría de repensar la idea de modernidad a partir de esta centralidad del arte. Lo relevante sería que las fuerzas antagónicas de lo funcional y lo expresivo se equilibran. La imaginación estética no se fortalece a costa de una merma de la pujante racionalidad finalista. En concreto, su irrupción obedece a un déficit crónico de la modernidad: la represión de la veta expresiva como aspecto sustantivo de la vida humana. La afectividad se reivindica y busca orificios en el vasto espacio social para visibilizarse. No se conforma con las relaciones íntimas y privadas. También se expande hacia lo profesional y lo institucional. De algún 
modo, se rebela ante un modelo social que distanciaba afectos y cálculo. Algo de esta rebelión se produce en perfiles profesionales de nuestro tiempo (emprendedores, empresarios, investigadores, etc.) que buscan alianzas entre ambos polos de la vida humana. La normalización de la creatividad exige el contacto y la integración de los recursos técnicos y del sustrato metafórico de la ensoñación imaginaria. El universo de la medida técnica se pone al servicio de la experimentación y las mezclas en todos los sectores de la sociedad y en el marco de la propia identidad.

En este sentido, la pregunta por la condición de la modernidad necesita buscar en otra dirección. El ethos calvinista del que hablaba Weber ya no rige desde el momento en que la racionalidad finalista y la imaginación artística constituyen "puntos extremos de un continuum" (Reckwitz, 2012: 28). Ninguna esencia, naturaleza o metafísica explica esa supuesta relación de oposición estructural entre ellos, salvo la entronización cultural de la productividad como núcleo de la forma de vida capitalista. El carácter histórico y social de esa relación antagónica se ha matizado en nuestros días ya que empiezan a observarse fecundos solapamientos entre ellos en determinados sectores de la sociedad. Los medios técnicos y el imaginario estético redefinen sus relaciones, al mismo tiempo, la modernidad se replantea su diseño. Esta ya no gira unilateralmente en torno al polo de la eficacia. La expresividad estéticamente canalizada reclama una posición central que le había sido negada en las fases iniciales de la modernidad. Elementos de la vida artística como el riesgo, la ruptura, lo inédito definen el nuevo tono de la estructura social. En ella resurge una de las almas de la modernidad cuya vitalidad ha sido silenciada por la veta ilustrada dominante: la romántica. Medida y sueño, separación y mezcla, conforman los recursos básicos de los nuevos creadores. Estos ya no son ni meros especialistas, ni actores entregados a la sola inspiración, sino más bien los cauces en los que ambas herencias se cruzan y fecundan. En otras palabras, la modernidad de la creatividad re-estetiza la experiencia contemporánea. Lejos de excluirla, integra en su actual disposición la dimensión onírica y experimental del gesto artístico.

Frente a los anuncios que pronosticaban la muerte de la modernidad y el nacimiento de la postmodernidad, es decir, la quiebra definitiva de la razón técnica dominadora y el surgimiento de una hiperestetización compensatoria, se ha producido un reequilibrio simbólico de las competencias estéticas e instrumentales fruto y producto de un movimiento endógeno de largo recorrido. Para su visualización hay que ir más allá del corto plazo y la inmediatez y analizar el tiempo largo que incluye procesos de formación, cambios y transformaciones sociales. No hablamos, por ello, de postmodernidad, en la que los excesos de la racionalidad instrumental dejan paso a simulacros estéticos y la desaparición de la realidad (Baudrillard, 1978), ni de otra modernidad, distinta y desvinculada de la nacida desde las tradiciones europeas románticas e ilustradas. Se trata de la misma pero con desarrollos postburgueses que desconciertan por su mutación estética y su pulsión creativa. Y se trata de la misma porque lo que ha ocurrido es el despertar y la consolidación, en términos estructurales, de la tradición romántica cuyo potencial simbólico había constituido el papel de nicho de la modernidad triunfante productivista. La burguesía apartó al artista hacia la periferia, disfrutó su producción creativa como complemento afectivo de su hiperactividad económica y 
estigmatizó al creador por su tendencia hacia la soledad, la extravagancia y el exceso. El fondo intelectual y especulativo de la Ilustración, más afín al modelo de acción basado en el criterio (cartesiano) de la racionalidad que separa y escinde (Durand, 1990), sometió a la mirada romántica de la modernidad que concibe su trato con el mundo desde el sustrato de una afectividad aglutinante y cohesiva. La propia modernidad ha vivido en nuestros días ese proceso de oscilación semántica interna desde el momento en que el fondo romántico busca un espacio de reconocimiento junto a las facultades especulativas de la Ilustración. El calado minoritario de la bohemia de las biografías artísticas se ha democratizado. Dicho de otro modo, se ha hecho normal y ubicuo.

Esto hasta el punto de que la democratización de la experiencia creativa puede entenderse como el nacimiento histórico de un ethos, en particular, el ethos creativo, ya no basado en el rigor y la planificación, sino en los ensayos, las mezclas y las pruebas tecnológicamente orientadas. Se trata de una novedosa moral del trabajo que prioriza, tanto los contenidos de la actividad, como un elevado grado de autenticidad y autodescubrimiento individual. Este tipo de organización de la acción, facilitado en buena medida por la expansión de la tecnología, se apoya en un episodio de ausencia de planificación y sorpresa. En cierto modo, tiene lugar el maridaje entre la innovación tecnológica y la creatividad estética. Los recursos tecnológicos se ponen al servicio de la originalidad a la que apunta el ethos creativo. Si bien la racionalidad técnica y la imaginación estética disponen de lógicas distintas, este modelo reclama una aproximación entre ambas sensibilidades. La racionalidad según fines puebla la vida contemporánea de instrumentos, medios, recursos técnicos que brindan sus servicios a la difusión de acontecimientos estéticos. Siempre que los instrumentos objetivos no se conviertan en fines en sí mismos y favorezcan, por el contrario, la visibilización de contenidos estéticos, estaríamos ante una experiencia de complementariedad fecunda entre sendos modos de racionalidad.

\section{Genealogía de la subjetividad creativa}

A continuación, se plantea la necesidad de exponer el proceso genealógico que describe la dinámica histórica generadora de la situación actual. A tal fin, Andreas Reckwitz (2012) ofrece un trabajo muy original y completo sobre los episodios históricos que se han dado hasta llegar a la expansión artística. Y lo hace sirviéndose de un conjunto de conceptos (nicho, contracultura, norma) que señalan los diferentes episodios del arte en el proceso de formación de la modernidad en su estado actual.

En los inicios de la modernidad el arte no ocupa un lugar relevante. Se trata del nicho en el que se incluyen aquellas figuras y actividades sociales moralmente desprestigiadas y alejadas de los procesos de producción. El maquinismo empieza a dominar a escala planetaria. El cálculo define la forma de conciencia de la modernidad incipiente. Si algún protagonismo recae sobre el arte es el de ser un instrumento de compensación emocional dentro de la erosión afectiva que genera el ethos burgués. De su actividad surgen deleite estético, entretenimiento social y liberación de la realidad. En ningún caso, influye sobre el statuo quo impuesto 
originalmente, en buena medida, por el dominante patrón económico de producción capitalista. La comunidad estética se sitúa en la bohemia donde el rigor profesional y la rectitud moral se debilitan y prevalece una laxitud ética y estética en los usos y rutinas de los actores. Se trata de espacios sociales dominados por perfiles sociales saturados de excentricidad debido a que actúan desde los momentos de inspiración mística y metafísica inaccesibles a la sola razón. Todos ellos forman parte de la figura del genio que, en el mundo incipientemente moderno, se sitúa en los márgenes de lo social porque sus creaciones nacen desde esferas que transgreden el umbral de la conciencia social. Conforman la existencia de una minoría creativa selecta carente de integración social ya que no ocupan espacio alguno en la taxonomía de las profesiones dirigidas exclusivamente hacia el mundo del trabajo remunerado. Su relevancia se constata en lo referido a la educación sentimental que permite dotar de códigos de pulcritud y refinamiento a la cultura burguesa. Ya en el seno de esta, a pesar de su carácter minoritario, la expresividad subjetiva asomaba en experiencias alejadas del cálculo burgués tales como la liturgia del amor romántico, el elogio de la vida campesina, expresiones incipientes de un cierto consumo burgués, etc. (Reckwitz, 2015: 34).

Con todo, en este contexto social surgen expresiones embrionarias de rechazo ante los excesos de la economía capitalista. La I Exposición Universal celebrada en 1851 en el Crystal Palace de Londres constituye un sensor de la magnificiencia arrolladora de la economía capitalista en campos como la arquitectura, el interiorismo, los objetos técnicos. Se trata de algo más que un mundo de mentalidad aplicada, también de ensoñación onírica que da vida a la novedosa deidad intramundana y profana que rige el destino de la modernidad secularizada: el consumo. Arts and Crafts es un movimiento que expresa una sensibilidad contraria a los excesos del capitalismo, en concreto, a la estandarización vigente en sus modelos productivos. De algún modo, abre la puerta a otros planteamientos en el trabajo y en el consumo. Su ideal es el de un modelo de trabajo que aproxima, en mayor medida, el trabajo y el arte a partir de un concepto como el de artesanía. Con él se pretende salvaguardar los objetos artesanales elaborados por el hombre y para el hombre del influjo finalista del ethos burgués, todo ello sin el dominio alienante de la producción donde los individuos (productores y usuarios) no orientan su comportamiento exclusivamente a los objetos y donde el proceso de producción alienta la autorrealización y el deleite personal en cada caso. Este movimiento da voz a una sensibilidad incipiente que ve representada en la actividad artesanal una estetización postromántica que vela por los derechos de lo motivacional en el mundo del trabajo y que glosaron en los inicios de la modernidad autores como Marx, Nietzsche, Emerson, entre otros.

Además de esta expresión crítica con las lógicas del capitalismo, surgieron otras que tienen lugar a mitad del siglo pasado. Esto se hace palpable coincidiendo con el nacimiento del sistema fordista. Si bien en sus inicios se instala en Estados Unidos sobre la base de la affluent society, el asentamiento del fordismo arraiga sobre un anatgonismo de inicio. Aunque sigue el curso racionalizador de la modernidad burguesa centrada en una sociedad rígidamente organizada, basada en la sistematización de la producción y elaborada desde el patrón de la Gran Corporación provista de una consistente jerarquización y diferenciación de funciones, de igual modo desata una incipiente estetización de las relaciones 
sociales. Los primeros actores que protagonizaron episodios de veneración y encantamiento del consumo masivo son las clases medias. En buena medida este episodio viene activado por una revolución técnica que transforma las condiciones cotidianas y permite el acceso generalizado a la ensoñación consumista. Esta se democratiza de modo paulatino hasta llegar a nuestros días como pauta de normalización.

En los turbulentos años 60 aparecen las primeras voces críticas a la forma de vida implantada por el fordismo. Frente a sus excesos reguladores y normativistas surge lo que Taylor denomina giro expresivista (2007: 539 y ss.) a través del cual la sociedad en su conjunto reclama un mayor espacio para la dimensión motivacional de la vida social. Primero en Estados Unidos y después en Europa y el resto del planeta, diferentes colectivos sociales exigen una corrección de gran alcance en la vida social de modo que la expresión y la vitalidad humana no quedan silenciadas por la planificación organizada del capitalismo fordista. El modelo al que apunta este giro es el del arte. En particular, el artista de las vanguardias funge como pauta y ejemplo de una vida cuyos fines y objetivos dejan espacio a la expresividad más íntima. Aquí el arte no rige como mera compensación afectiva o espectáculo, sino como momento irrenunciable de una vida plena, de una vida que se expresa en sus obras y producciones. La narrativa biográfica compuesta de sueños, ambiciones, proyectos y frustraciones surge de la creatividad artística. En ella se dan las condiciones para pensar la vida como un conjunto orgánico.

En este nuevo horizonte social se detecta una mutación axiológica surgida del cruce de la herencia del romanticismo y las vanguardias de principios de siglo. La preocupación por la vida venidera deja espacio a la densidad inabarcable del ahora histórico y social. La novedad radica en un proceso de expansión de la vida creativa afín a la intensidad del momento, la irrupción de la veta expresiva y la lucha visceral contra la rutina y la repetición. La creatividad ya no es monopolio de una minoría especialmente dotada y sensible a la novedad, sino el soporte básico de un individuo que se crea a sí mismo. La creatividad individual y el rechazo al orden burgués promueven la transformación de la vida artística en embrión de la contracultura a través de la cual se multiplican las expresiones de modelos de sociedad alternativos al fordista. Lo que hasta ese momento eran episodios aislados de rechazo pasan a ser desencadenantes de un profundo cambio de valores. Temas como la cuestión climática, el feminismo, los derechos de las minorías culturales, etc., se convierten en banderas de una sociedad plural cuya diversidad comparte la crítica al mundo fordista.

Este contexto de profundo cambio en la sociedad moderna favorece la transformación de la creatividad artística en norma. La novedad radica en el realce del arte en los procesos de producción del capitalismo estético. Frente a las posiciones de nicho y luego contracultura, la creatividad de la bohemia adquiere una posición preeminente en la sociedad y deviene normalizadora. Una de sus máximas expresiones es la idea de innovación como episodio creativo del presente que favorece en sus búsquedas y sus hallazgos un crecimiento de la prosperidad social. En él conviven el arte y la técnica. Esta pone a disposición de la inspiración creativa de los actores todo su arsenal instrumental. La imaginación y el cálculo se complementan. El antagonismo tecnología-creatividad artística ya no rige. Se 
cruzan y dan muestra de su fecundidad en diferentes sectores de la sociedad. Las rígidas fronteras de la modernidad burguesa se descomponen. En ejemplos como un nuevo modelo automovilístico, gastronómico, publicitario, arquitectónico cuesta identificar dónde termina la tecnología y empieza la imaginación artística.

De algún modo, el arte coloniza diferentes espacios de la vida social. Con él se abren espacios de autoexpresión afectiva pero también se estabiliza la expectativa social de la creatividad como norma. Además de experiencia de liberación, la creatividad deviene exigencia y coacción. Demanda originalidad sin atender a orígenes sociales, extracción social, niveles de formación, etc. Se visibiliza el imperativo creativo. Reckwitz expresa la paradoja que consiste en la transformación de la liberación expresiva del arte en la contracción opresiva derivada de su normalización. La creatividad consiste en un tipo de normalización de "segundo orden" (Reckwitz, 2012: 46), que no remite al mundo foucaultiano de la domesticación corporal, sino a la necesidad compulsiva de desbordar lo conocido a base de sugerir originalidad y novedad.

En este orden de cosas pueden analizarse las transiciones de la idea de creatividad en nuestros modelos sociales. Un foco de interés destacado lo aporta la psicología. Este campo científico se ha ocupado de popularizar y democratizar la experiencia creativa en el curso de los últimos años (Foucault, 1999; Giddens, 2000; Illouz, 2007). Su discurso científico, así como el de dominios científicos cercanos, como el de la psiquiatría, el psicoanálisis y los numerosos modelos de psicoterapia, han favorecido, desde los años 20 del siglo pasado, las interpretaciones del sujeto que le definen como ser básicamente creativo, al igual que la percepción popular de lo que debe ser un self exitoso y una orientación vital deseable, nociones especialmente arraigadas entre las clases medias académicas. En el curso sucesivo de los diferentes enfoques de la ciencia psicológica del último siglo como son el psicoanálisis, la Gestalt, la psicología del autocrecimiento y la psicología de la investigación de la inteligencia, se constata una transición desde una imagen del artista genial, valorado por su personalidad excéntrica dirigida contra el desencantamiento del mundo burgués y capaz de sublimar creativamente los complejos inconscientes del hombre moderno, hacia una visión del artista en la que la experiencia creadora provoca un tipo de personalidad inestable, enfrentada a todo lo definido como convencional e incapaz de sobrellevar lúcidamente sus procesos afectivos y emocionales.

La figura del genio se patologiza. Desde los años 40 la psicología investiga en la línea de una idea de creatividad que no separa y escinde lo racional y lo imaginario, sino que integra creativamente ambos polos bajo una visión integradora del individuo. La idea de autorrealización y de autocrecimiento (selfgrowth psychology) de los años 50, que representan Abraham Maslow, Rollo May, también Erich Fromm y Herbert Marcuse, va en esta dirección en la que la creatividad no se orienta hacia la excelencia estética, sino hacia el bienestar humano logrado por personalidades que han mostrado la capacidad de reorientar creativamente las reacciones psicológicas patológicas. Aquí la creatividad "no se refiere a un acto extraordinario de lo creativo o a una competencia cognitiva de resolución de problemas, sino a la constante transformación de la percepción cotidiana, selectiva, simple, en percepción total y «densa»" (Reckwitz, 2012: 224). El trance creativo surge en lo normal y lo cotidiano. Es algo ordinario. Ya no parte, 
ni surge de mentes prodigiosas, sino de una mirada atenta a la complejidad y las relaciones entre las cosas mundanas. Brota "del flujo de la praxis activa que se origina en situaciones concretas" (Ibidem: 229). La noción de flow de Csíkszentmihalyi (1990) y de inteligencia emocional de Goleman (1996) expresan esta metamorfosis centrada en una nueva idea de la realidad más cercana a lo dinámico, lo sorprendente, lo azaroso y lo aleatorio incorporado a la experiencia cotidiana.

\section{Crítica de la creatividad}

La sociedad centrada en los actos creativos no escapa a los procesos de alienación inherentes a toda forma de sociedad. También la creatividad desata fenómenos contrarios a la expansión de la originalidad y el logro de la plenitud afectiva. Esto sorprende en mayor medida porque cuesta creer que la difusión de esta experiencia benefactora y liberadora genere, en muchos casos, su efecto contrario, es decir, expresiones de opresión, desigualdad, frustración, parálisis y exclusión. Pero desde el momento en que la creatividad deviene norma, se incorpora a la vida social el trazado de un límite que separa dentro y fuera, una zona de inclusión y otra de exclusión. El dato inédito de la creatividad convertido en sustrato imaginario de la sociedad genera, así mismo, vidas y biografías alejadas de la plenitud creativa, ajenas al premio social del reconocimiento público y autoclausuradas en la frustración y la culpa. Junto a la promoción de la libertad de experimentación, la innovación científica y el autodesarrollo personal, se anuncian los efectos perversos derivados de la transformación de la idea de creatividad en imperativo social. Desde el momento en que se trazan nuevos contornos que definen los espacios de la inclusión y la exclusión de la vida social, ni la propia idea de creatividad puede quedar al margen de la aparición de la diferencia y el conflicto social. No vivimos en el reino de la libertad, sino en un contexto que lleva en su seno el lastre de nuevas formas de cosificación.

En este sentido, es necesaria la tarea de la crítica de la sociedad o, como afirma Stefan Nowotny, "una crítica cre-activa de la creatividad" (2011: 18), que incluya los distintos planos de la vida social que quedan fuera del horizonte de la experiencia creativa contemporánea. En la medida en que este se erige en el centro denso de la convivencia se genera una nueva periferia en la que ya no destaca la vida bohemia de los artistas geniales, sino nuevos problemas y perfiles que el análisis social y filosófico debe desvelar.

En un primer plano, podría hablarse de problemas regionales surgidos en los entornos de la vida creativa. Hechos como la desigualdad de opciones estéticas, en especial, entre clases con distintos y desiguales volúmenes y estructuras en el capital económico, cultural, social y temporal, la hegemonía cultural en la praxis estética encarnada en pautas y modelos de creación dominantes como, por ejemplo, la alta cultura y la cultura popular frente a estéticas sub-culturales y nooccidentales, la hegemonía estructural de la praxis estética que prioriza la creación dirigida al público en términos de innovación en detrimento de la repetición y la creatividad solitaria, la conversión de la estética en medio (de propaganda política o publicitaria) para una finalidad externa (electoral o puramente económica) o la 
promoción de prácticas sociales en las que la sobreabundancia de estímulos estéticos no encaja ni se integra en los cometidos rutinarios de la praxis instrumental o se convierte en mero elemento de embellecimiento formal o suntuario, expresan zonas de la sociedad contemporánea en las que la creatividad produce controversia y debate social.

En un segundo plano, podría tenerse en cuenta un modelo de crítica social referido al cuerpo o al conjunto de la sociedad como un todo y en el que el núcleo del debate sería hasta qué punto la creatividad estética oscurece y olvida $s u$ condición de creación social. En alusión a los distintos dominios semánticos de la creatividad que se plantearon al inicio de este trabajo, esta argumentación crítica pone en cuestión el peligro derivado de que la creatividad estética se cierre sobre sí misma y rompa cualquier vínculo con esas otras esferas de la creatividad que son estructurales y que la constituyen. Este marco social, como cualquier otro surgido históricamente, tiende a ser autorreferencial y desconocedor de los procesos genealógicos que le dieron vida y le inauguraron. Pero su existencia no responde a una voluntad metafísica ni a procesos mecánicos de secularización o progreso. Es producto de las prácticas y las interacciones sociales en las que confluyen esas otras dimensiones de la creatividad como una idea del ser por-ser, el descubrimiento histórico-evolutivo de la competencia creativa en el hombre en el tiempo axial y la dimensión renovadora de toda acción social. Dicho de otro modo, la dimensión estética de nuestro tiempo no agota ni supera los otros dominios de la creatividad inherentes a la génesis de toda forma social que convierten el problema de la creatividad en algo mucho más complejo que lo que sugiere la normalización estética de nuestro tiempo.

Este planteamiento ofrece la posibilidad de descubrir el carácter contingente de este modelo de sociedad y, por ende, políticamente debatible y rebatible. A falta de crítica social la realidad rutinaria se sublima en entidad metafísica ajena al paso del tiempo y al cambio social. Pero desde el punto de vista de la crítica de la creatividad la actualidad histórica no supone el final de la historia, ni la victoria definitiva de la liberación humana. Muy al contrario, se trata de una forma de vida que nace y degenerará producto de la contingencia que la engendró. La avalancha estética de la actualidad puede hacer creer que el hiperactivismo creativo y la omnipresente innovación técnica constituyen estímulos de cambio y avance social. Cuando, en realidad, el mayor desafío del tiempo presente es, en términos marcusianos, la unidimensionalización estética, que, por momentos, recubre y acalla otras dimensiones de la creatividad que desactivan sus pulsiones normativas y dominadoras y que incitan a la recreación y la corrección política de las instancias coactivas de la sociedad actual.

\section{Bibliografía}

Arendt, H. (1998): Sobre la revolución, Madrid, Alianza.

Baudrillard, J. (1978): Cultura y simulacro, Barcelona, Kairós.

Bell, D. (1998): Las contradicciones culturales del capitalismo, Madrid, Alianza Universidad. 
Bellah, R. N. (2011): Religion in Human Evolution, Cambridge (Mass.), The Belknap Press of Harvard University Press.

Benjamin, W. (1982): Discursos interrumpidos I, Madrid, Taurus.

Benjamin, W. (1984): Poesía y capitalismo, Madrid, Taurus.

Bourdieu, P. (1981): El sentido práctico, Madrid, Taurus.

Castoriadis, C. (1989): La institución imaginaria de la sociedad (2 vol.), Barcelona, Tusquets.

Castoriadis, C. (1988): Los dominios del hombre: las encrucijadas del laberinto, Barcelona, Gedisa.

Conrad, S. y S. Randeria, eds., (2002): Jenseits des Eurozentrismus, Fráncfort del Meno, Campus Verlag.

Critchley, S. (2014): Tragedia y modernidad, Madrid, Trotta.

Csíkszentmihályi, M. (1990): Flow. Psychological of Optimal Experience, New York, Harper.

Donald, M. (1991): Origins of the Modern Mind: Three Stages in the Evolution of Culture and Cognition, Cambridge (Mass.), Harvard University Press.

Durand, G. (1990): Las estructuras antropológicas de lo imaginario, Buenos Aires, F.C.E.

Durkheim, É. (1992): Las formas elementales de la vida religiosa, Madrid, Akal.

Eisenstadt, S. N., ed., (1986): The Origins and Diversity of Axial Age Civilizations, New York, State University of New York.

Elkana, Y. (1986): "The Emergence of Second-Order Thinking”, en S. N. Eisenstadt, ed., The Origins and Diversity of Axial Age Civilizations, New York, State University of New York, pp. 40-64.

Florida, R. (2010): La clase creativa, Barcelona, Paidós.

Foucault, M. (1999): Estética, ética y hermenéutica, Barcelona, Paidós.

Giddens, A. (1997): La constitución de la sociedad, Buenos Aires, Amorrortu.

Giddens, A. (2000): Modernidad e identidad del yo, Barcelona, Península.

Goleman, D. (1996): Emotional Intelligence, New York, Bantam Books.

Han, B.-Ch. (2016): La salvación de lo bello, Barcelona, Herder.

Harvey, D. (1998): La condición de la postmodernidad, Buenos Aires, Amorrortu.

Heubel, F. (2002): Das Dispositiv der Kreativität, Darmstadt, Wissenschaftliche Buchgesellschaft.

Huntington, S. (2001): El choque de civilizaciones, Buenos Aires, Paidós.

Illouz, E. (2007): Intimidades congeladas, Buenos Aires, Katz.

Jaspers, K. (1965): Origen y meta de la historia, Madrid, Revista de Occidente.

Joas, H. (1992): Die Kreativität des Handelns, Fráncfort del Meno, Suhrkamp.

Kant, I. (1999): Crítica del juicio, Madrid, Austral.

Knöbl, W. (2011): "Makrotheorie zwischen Pragmatismus und Historismus", en B.

Hollstein, M. Jung y W. Knöbl, eds., en Handlung und Erfahrung, Fráncfort del Meno, Campus, pp. 273-315.

Koppetsch, C. (2006): Das Ethos der Kreativen, Constanza, UVK.

Koselleck, R. (1993): Futuro pasado, Barcelona, Paidós.

Lyotard, F. (1987): La condición postmoderna, Madrid, Cátedra.

Maffesoli, M. (1996): De la orgía, Barcelona, Ariel.

Raunig, G, G. Ray y U. Wuggenig, eds., (2011): Critique of creativity, Londres, MyFlyBooks.

Reckwitz, A., (2010): Das hybride Subjekt, Weilerwist, Velbrück Wissenschaft. 
Reckwitz, A. (2012): Die Erfindung der Kreativität, Fráncfort del Meno, Suhrkamp.

Reckwitz, A. (2015): “Ästhetik und Gesellschaft -ein analytischer Bezugrahmen”, en A. Reckwitz, S. Prinz y H. Schäfer, eds., Ästhetik und Gesellschaft”, Fráncfort del Meno, Suhrkamp, pp. 13-52.

Rorty, R. (1991): Contingencia, ironía y solidaridad, Barcelona. Paidós.

Schmidt, V.H. (2006): "Multiples Modernities or Varities of Modernity?", Current Sociology, 54, pp. 77-97.

Schwartz, B. (1975): "The Age of Transcendence", Daedalus, 104-2, pp. 1-17.

Taylor, Ch. (2006): Las fuentes del yo, Barcelona, Paidós.

Taylor, Ch. (2007): A Secular Age, Cambridge (Mass.), The Belknap Press of Harvard Press.

Touraine, A. (1987): Regreso del actor, Buenos Aires, Eudeba.

Toynbee, A.J. (1981): Estudio de la historia, vol.1, Madrid, Alianza.

Weber, M. (1987): Economía y sociedad, México, FCE. 